\title{
Investigating the effectiveness of public subsidies to hotels: Evidence from an Alpine region
}

\author{
Enrico Tundis $^{\mathrm{a}}$ b, , Roberto Gabriele ${ }^{\mathrm{a}}$, Enrico Zaninotto ${ }^{\mathrm{a}}$ \\ ${ }^{a}$ Department of Economics and Management, University of Trento, Via Inama 5, 38122 Trento, Italy \\ ${ }^{\mathrm{b}}$ Istituto di Statistica della Provincia Autonoma di Trento (ISPAT), Trento, Italy
}

\section{A R T I C L E IN F O}

\section{Article history:}

Received 5 April 2016

Received in revised form 14 March

2017

Accepted 17 March 2017

Available online xxx

Keywords:

Hotel industry

Public subsidies

Regional policy

matching estimators

\begin{abstract}
A B S T R A C T
This paper investigates the effect of capital public subsidies on hotels' performance. The empirical domain of analysis is the hotel industry in the Trentino province of Italy and the subsidies granted therein by the local government. The objective variables of the study are typical performance indicators, i.e., productivity, profitability, occupancy rate, and demand variability. A conditional difference-in-differences estimator is used to estimate causal effects by controlling for observed and time-invariant unobserved hotel heterogeneity. Public subsidies have a positive effect on hotel performance. This effect is, however, greater in highly attractive destinations than in less attractive ones, with public intervention potentially increasing the divide between the two.
\end{abstract}

(C) 2016 Published by Elsevier Ltd.

\section{Introduction}

Tourism is one of the main determinants of countries' growth (Balaguer \& Cantavella-Jorda, 2002; Lee \& Chang, 2008) and one of the major factors for regional development (Andraz, Norte, \& Gonçalves, 2015; Brida \& Giuliani, 2013; Paci \& Marrocu, 2014). Consequently, tourism policy is becoming an instrument for economic development (Estol \& Font, 2016). Many initiatives in support of tourism are included in supranational programs, such as the European Regional Development Fund to support the competitiveness and sustainability of tourism, as well as at national and regional levels (Bernini \& Pellegrini, 2013; Fleischer \& Felsenstein, 2004; Logar, 2010; Thomas, 1994; Wanhill, 2000).

The tourism industry is an example of a place-based approach to regional development. This is broadly defined as "government efforts to enhance the economic performance of an area within its jurisdiction" (Neumark \& Simpson, 2014, p. 1; Barca, McCann, \& Rodríguez-Pose, 2012). Public interventions take on various forms, ranging from regulatory actions to the direct provision of funds (i.e., subsidies) to private firms. Subsidies in the tourism industry were indeed mentioned by 62 of the 97 members of the World Trade Association between 1995 and 2004 (WTO, 2006), and the most mentioned goal of support for tourism was regional development. Among the place-based policies in tourism, the support of hotel investments is widely used. Corresponding author at: Department of Economics and Management, University of
Trento, Via Inama 5, 38122 Trento, Italy.
Despite the wide use of the public support of hotel investments, the effect of public intervention is still an issue (OECD, 2014). Quantitative analysis on the efficacy of subsidization policies for hotels remains scant and does not cover small firms in a regional context (see, e.g., Bernini \& Pellegrini, 2013). The large body of literature on policy evaluation demonstrates that subsidy programs can often be ineffective because they do not modify the behavior of the decision unit, and they can even be detrimental, introducing distortions into the competitive arena (Buigues \& Sekkat, 2011; Weiermair, 2006; Zúñiga-Vicente, Alonso-Borrego, Forcadell, \& Galán, 2014).

A more detailed analysis of the effect of subsidies to hotels would help policymakers implement evidence-based policies for the tourism industry (OECD, 2010). However, a comparison between the investment behavior of subsidized and unsubsidized hotels is not sufficient to assess the positive impact of the policy. Indeed, firms with a higher propensity to invest can self-select to reap public incentives. It might be the case that subsidized hotels invested independent on the subsidy, or that hotels merely anticipate investment decisions that had been made anyway. Finally, it could also be the case that incentivized hotels invest in low-performance activities. For this reason, subsidized hotels were matched with unsubsidized ones having similar observable characteristics, namely the legal form, the size, the category, the level of external services, the international attractiveness, the capital intensity, and location factors. Moreover, a conditional difference-in-differences estimation is employed to control for unobservable time-invariant factors as well.

The main goal of this paper is to provide evidence for the effectiveness of public subsidies for micro and small hotels in a regional context. More specifically, the main question addressed in this paper is whether public subsidies aimed at co-financing hotel investments 
are beneficial in terms of inducing them to increase their investment with clear effects on their productivity, profitability, occupancy rate, and demand variability.

\section{Public policy in tourism}

Public interventions in tourism may take on various forms. While in developing countries subsidies for the development of tourism relate mostly to infrastructure improvements, in developed countries the support for the tourism industry generally takes the form of support for small tourism firms, and hotels among them (WTO, 2006). Small tourism firms are seen as fundamental for the development of the sector (Thomas, Shaw, \& Page, 2011). Micro and small firms represent the bulk of the tourism industry supply in many European destinations $(\mathrm{OECD}, 2010)^{1}$. In particular, most hotels in the major European countries (90\% In France, $85 \%$ in Italy, $75 \%$ in Germany, $80 \%$ in Spain) are classifiable as micro firms. The arguments advanced in favor of targeting policy interventions in small tourism firms lie in the market failures caused by a high degree of fragmentation in the industry and asymmetric information (Croes \& Severt, 2007; Wanhill, 2000). In principle, small firms are flexible and can adapt more easily to the changing needs of visitors. On the other hand, however, small firms often have limited resources available that may restrict their investments and ability to adapt rapidly to new challenges and to capture opportunities. In particular, small firms' access to capital markets is more difficult (Wanhill, 2000).

The assessment of the effects of the direct provision of support to tourism firms through public subsidies has been analyzed using different approaches. Schubert and Brida (2008) theoretically studied the impact of the subsidization policy in the tourism sector by means of a dynamic general equilibrium model. Their analysis showed how, under certain conditions, subsidies might have a positive effect in the short run, which decreases as time passes. Using a qualitative approach, Logar (2010) compared the use of a set of policy instruments available to policymakers for managing tourism in a local context. Although the use of subsidies is seen as effective and highly acceptable, concerns arise about their economic feasibility due to government budget constraints. Fleischer and Felsenstein (2004) used a regression approach to uncover the employment and output effects of capital subsidy directed to small tourism firms. They analyzed a loan guarantee scheme to provide capital assistance to tourism firms and found that public assistance affected small tourism firms more strongly than other small firms, and that the effect was higher on employment than on output growth.

The evaluation of subsidization policies must cope with endogeneity and self-selection issues. Subsidies are generally not allocated randomly to firms. In fact, only some firms can decide to apply to obtain public funding. On the other hand, policymakers select which firms (the projects) they will support. Few empirical studies, however, have explicitly addressed the problem of selection in the access to subsidization plans in tourism. Bernini and Pellegrini (2013) carried out a quantitative evaluation of the effectiveness of public subsidies for tourism firms using a sample of Italian corporations that applied for financial aid via the Italian law 488/1992. A matching procedure was employed to overcome selection bias, with subsidized and control firms matched using propensity scores (i.e., the probability of receiving a subsidy given a set of observable firm characteristics). Their main findings show that subsidized firms had higher output and employment growth, but lower labor productivity than unsub-

\footnotetext{
${ }^{1}$ Firms are classified with respect to the number of employees. In particular, small firms are those with fewer than 50 employees, while micro firms have at most 10 employees.
}

sidized ones. Moreover, these impacts varied across destinations. This analysis was, however, restricted to medium-large firms, and the authors emphasize that their results cannot be extended to small firms.

Building on a preliminary exploratory work (Gabriele, Tundis, \& Zaninotto, 2016), this study tests a set of hypotheses on the effect of subsidies on some hotels' performance indicators, controlling for self-selection and the local context.

\section{The effect of capital subsidies on hotel performance}

The expected effect of capital subsidies on hotel performance can be understood by considering the influence on the innovative behavior of hotels. Investment in new capital is a key source of innovation for supplier-dominated sectors, as in many service sectors (Hipp \& Grupp, 2005; Sirilli \& Evangelista, 1998). In particular, innovation and property renovation are intertwined in the hotel industry (Hassanien \& Baum, 2002). This is due to the fact that new capital may spur process, product, and service innovations. Hjalager (2010) refers to product or service innovations in tourism as the changes of a particular firm observed by the customer that are regarded as new, while process innovation is typically concerned with back-office operation with the aim of enhancing efficiency, productivity, and flow. Small hotels should opt for a focused instead of a holistic approach to innovation (Mattsson \& OrfilaSintes, 2014). Innovation in small hotels can be directed to the improvement of facilities, aimed at enlarging the portfolio of services delivered and increasing the quality of tourist experience, or accede to new segments of demand. This happens through the introduction of wellness facilities, superior architectural design, or new equipment (Pikkemaat, 2008). Improved capital, such as new kitchen equipment or increased room facilities (Orfila-Sintes, Crespí-Cladera, \& Martínez-Ros, 2005), can improve the quality of products and services delivered, which will in turn enhance demand. The availability of hotel comforts and high-quality facilities plays a key role in tourists' buying decisions (Choi \& Chu, 1999; Kashyap \& Bojanic, 2000), and improved capital endowment would increase the value of service experienced by tourists (Israeli, 2002). New segments of demand can be approached and new needs met. For instance, ageing clients can be sensitive to the innovation of accessibility, or the use of domotics, while environmental concerns can be met by investment in energy-saving and environment friendly facilities. Renewed physical capital may thus allow a hotel to attain lower costs and output with higher quality (Orfila-Sintes \& Mattsson, 2009).

Empirical research suggests that in the hotel industry, the introduction of new technology improves labor productivity and enhances revenues (Blake, Sinclair, \& Soria, 2006; Orfila-Sintes et al., 2005; Sheldon, 1983; Sundbo, Orfila-Sintes, \& Sørensen, 2007). Productivity reflects either the more efficient use of resources or an increase in the quantity or quality of output. The improvement of equipment aimed at increasing the quality of services or the introduction of new technologies can boost both drivers of productivity. Therefore, public policies supporting hotel investments are expected to be beneficial for hotel performance. Hence, the following hypothesis can be stated:

\section{Hypothesis 1a}

A public subsidy for hotel investment induces an increase in the labor productivity in subsidized hotels.

Moreover, for small hotels in particular, focusing specifically on service and back-office innovation through the integration of more advanced technological and physical assets appears to be an effective way to improve profitability and occupancy rates (Mattsson \& OrfilaSintes, 2014). Consequently, the following hypothesis is pro- 
posed:

\section{Hypothesis 1b}

A public subsidy for hotel investment induces an increase in the profitability and occupancy in subsidized hotels.

A desirable complementary aim of a public policy for hotels should be to reduce demand seasonality. Variations in the product mix obtained by adding additional services and facilities can increase the attractiveness of hotels during off-peak months, attracting new customers less sensible to seasonality. Therefore, public subsidies may also be effective for tackling seasonality problems:

\section{Hypothesis 1c}

A public subsidy to investment allows better demand management in subsidized hotels.

Hotel performance is influenced by the interplay of internal and external factors (Molina-Azorin, Pereira-Moliner, \& Claver-Cortés, 2010; Yang \& Cai, 2016). In particular, the relationship between the quality of facilities and hotel outcomes can be moderated by destination features. Destination endowment in terms of natural and human landscapes, the business and shopping environment, scenery, and climate factors may provide additional experiential value to tourists and influence visitors' likelihood to return to the destination and extend their stay at the hotel (Bigné, Sánchez, \& Sánchez, 2001; Borodako \& Rudnicki, 2014; Cocklin, Harte, \& Hay, 1990). Likewise, hotels can take advantage of destination management policies aimed at promoting the destination during off-peak seasons (Baum \& Hagen, 1999). On the other hand, it is also possible that for hotels located in less attractive destinations, there is more room for improvement. If this were the case, a public subsidy could be used to promote catching up and convergence between destinations. Hence, the geographic specificity should influence the marginal return of policies directed toward hotels, allowing the following:

\section{Hypothesis 2}

For a hotel, the effect of receiving a subsidy is moderated (positively or negatively) by the attractiveness of the destination.

\section{The context of analysis}

The analysis is carried out on the hotel industry in the Italian province of Trento, one of the most important touristic areas in the northern region of Italy. Fig. 1 shows the geographical position of the province in the middle of the Alps. This empirical domain has two significant advantages. First, the reduced geographical dimension and the focus on a single, narrowly defined sector, ensures high comparability between subsidized and unsubsidized hotels. Second, hotels operating in Trentino receive grants only from the local government, thus avoiding confounding effects.

The province spans more than 14 tourist destinations (Fig. 2). The hotel industry in the province is characterized by the widespread presence of micro and small hotels that are unevenly spatially distributed, the majority being concentrated around lakes or in high mountain areas.

Tourism policies in Trentino are implemented under the umbrella of the Provincial Law 6/99 (PL 6/99), a public intervention aimed at stimulating investment activity of firms operating in the province. The public administration supports hotels' investment in the setting-up, extension, modernization, restructuring, and reactivation of hotel properties and is directed toward improving environmental sustainability. The main objective of public intervention is furthering the sustainable growth of the local economy through increasing the productivity and competitiveness of firms. The support for hotels was realized as capital grants given directly to hotels. The amount of financial aid is a fixed share of investment made by hotels. Specifically, the part of investment co-financed is up to $35 \%$ of the total amount needed, depending on the hotel size, i.e., hotels with the same size receive the same share of co-financing, and smaller hotels receive more aids. The median value of co-financing is about 25.000 Euros.

Hotels operating in the Trentino province must follow a formal application process for obtaining a PL6/99 grant. According to the magnitude of investment, applications receive two different types of assessment: evaluation-based or automatic. For applications for more than $500,000 € \mathrm{~s}$, an evaluation-based assessment is used, while requests of lower amounts are generally granted by the automatic procedure. In both cases, a hotel must submit a detailed project to the local authority. Independent of the type of assessment, each applicant must provide information on the firm, the objective, and a technical report of the investment project, the documents that ensure that the project meets environmental and planning law requirements, and the list of project costs. For the evaluation-based assessment, the balance sheets related to the previous two years as well as a business plan are requested to evaluate the economic viability and financial sustainability of the project. The costs that the applicants must meet are mainly related to the administrative costs associated with the application procedure and the cost of the service possibly provided by external consultants (e.g., the compilation of technical report or accounting advices). All projects are evaluated on a first-in-first-out rule, up to the overall budget exhaustion. Notwithstanding, most of the applicants that requested funding got financed, irrespective of the type of assessment (around $12 \%$ of applications were not financed). This fact is consistent with the aim of the policy of boosting the overall competitiveness of the province and suggests that the main source of selection bias can be found in the self-selection of the hotels: eventually, better hotels can be more active in trying to find public co-financing.

\section{Data}

Several sources were used to construct the database for this study. Administrative archives held by the local government were the primary sources of information on hotels that received grants through the PL6/99. In particular, the primary data on firm applications for public subsidies came from the APIAE (Agenzia provinciale per l'incentivazione attività economiche), which is the administrative body that manages the subsidization program on behalf of the local government. The APIAE archives allowed us to recover all hotels' applications. For each application, it was possible to retrieve information on the applicant, the date of submission and of assessment/approval, the type of subsidization procedure (selective or automatic), the final outcome of the application assessment (obtained, rejected, other outcome). In this study, both selective and automatic procedures are considered.

Information on hotels' characteristics (e.g., revenue and cost figures, legal forms, structural characteristics, location) were obtained from an extensive dataset built in partnership with ISPAT, the Statistical Office of Trentino (see Corsino, Mirabella, Tundis, \& Zaninotto, 2011).

The local government defined the policy under scrutiny in 1999 . The analysis focused on the period of 2002-2006. This period was chosen for two reasons. First, since the aim was to study the pure effect of policy, it was appropriate to look at the years just after the necessary period for the policy to become definitely operative. Second, by ending the time span of the analysis in 2006, the potential 


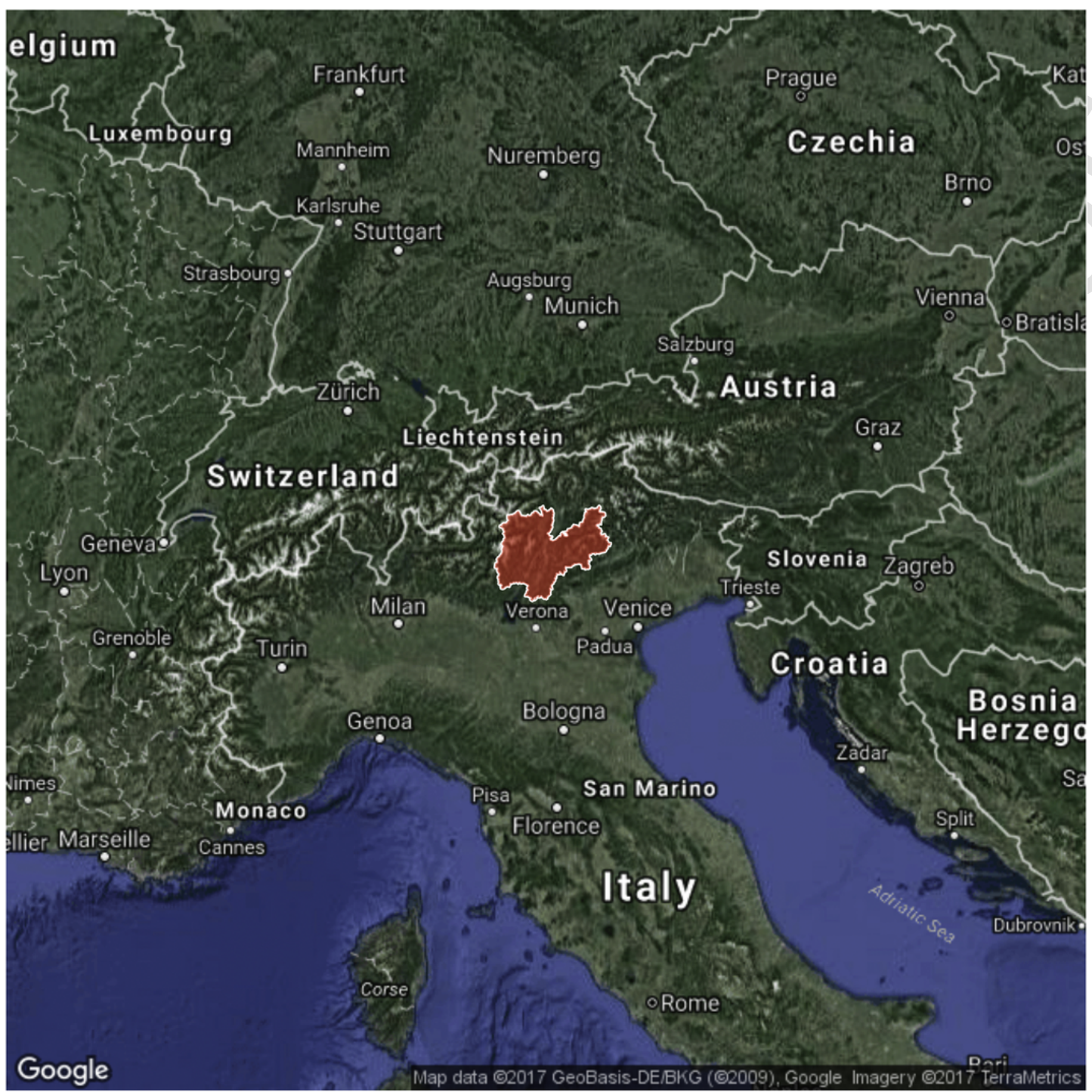

Fig. 1. Geographical position of the Trentino province.

negative influences of the economic downturn starting from 2007 were avoided.

The analysis was carried out on 154 subsidized hotels that received only one subsidy during 2002-2006. As for the control sample, eligible control units were hotels that did not receive subsidies during the period of analysis. After a preliminary screening and further controls, 372 unsubsidized hotels were left.

\section{Method}

The aim is to evaluate the effects of a treatment (the subsidy, in our case) not just with respect to the whole population of hotels, but specifically for those hotels that actually received it. The causal effect of a subsidy on a hotel's performance is thus estimated by considering the average treatment effect on the treated (ATT), a parameter of major interest for policy evaluation (Bernini \& Pellegrini, 2013; Imbens, 2004). It measures how much hotels that actually received a subsidy benefited from it, on average.

The main problem in estimating ATT is that for each hotel, the outcome is observed only under one treatment status (either subsidized or unsubsidized), while the outcome under the alternative treat- ment status (the counterfactual outcome) is not observed. Since hotels are not randomly assigned to treatment, the comparison of the mean difference of the outcome between subsidized and unsubsidized hotels will lead to the biased estimation of causal effects due to self-selection or selection enforced by the policy. In other words, the observed effect may depend on pre-existing differences between subsidized and unsubsidized hotels; that is, it may capture outcome differences between the two groups that cannot be attributed to the policy.

A commonly used method in policy evaluation studies to reduce selection bias is the matching approach (Abadie \& Imbens, 2002; Imbens, 2004). The underlying idea of matching methods is to imitate an experiment in which identical units are compared under the treated and untreated status. In the context under analysis, such an experiment can be simulated if it is possible to identify for each hotel that receives a subsidy one or more "twin" hotels that did not. Under the conditional independence assumption (Rubin, 1977, 1986), a "twin" hotel can be found among unsubsidized hotels with an identical, or very similar, set of observable characteristics related to the treatment status and the outcome. The matching method compares the outcomes of subsidized hotels (the treated group) with those of matched unsubsidized, i.e., the control group. 


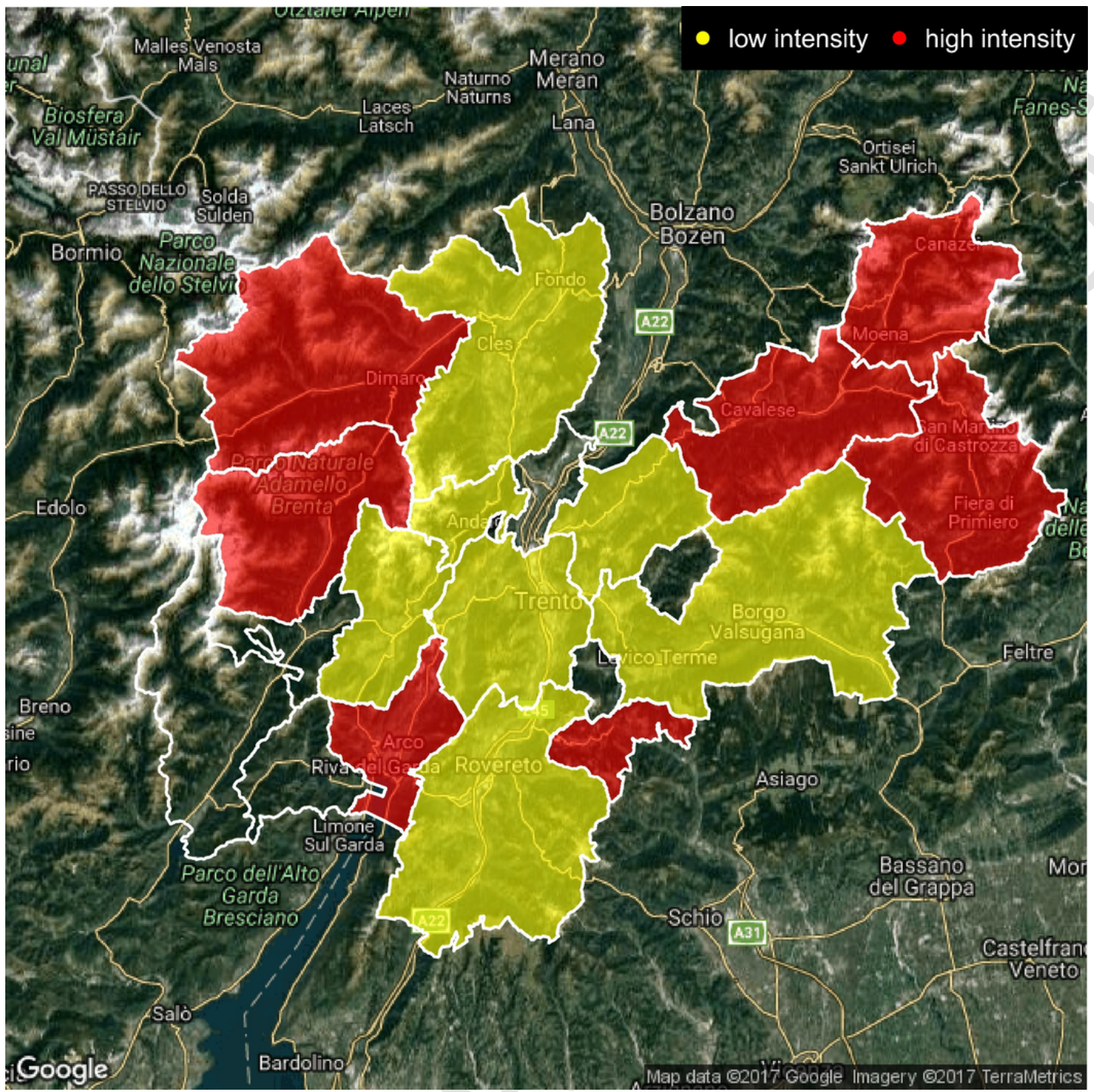

Fig. 2. Intensity of tourism across tourist destinations in the Trentino province.

Several procedures are used to match observations of the treated and control groups (Stuart, 2010). In this study, the nearest-neighbor matching estimator introduced by Abadie and Imbens (2002) and Imbens (2004) is employed. This estimator is preferable over the propensity score matching estimator (PSM) in terms of the model dependence and bias of results in contexts like the one under scrutiny, which presents a low level of imbalance and a limited number of treated units ${ }^{2}$. It allows for matching over a set of covariates that are mapped in a single index according to the vector norm $\mathrm{x} v=\left(\mathrm{x}^{\prime} V \mathrm{x}\right)^{1 / 2}$, where $V$ is a positive definite variance matrix used to weigh variables via normalization by their standard deviation. The distance between two units is obtained as $\|\mathrm{w}-\mathrm{x}\| V$, where $\mathbf{w}$ and $\mathbf{x}$ are the vectors of observable characteristics for the two units. The treated units are thus matched with the closest untreated units.

\footnotetext{
${ }^{2}$ More precisely, theorems related to PSM do not apply to finite samples (King \& Nielsen, 2016). The chosen estimator allows instead for exact matching without increasing the imbalance of the sample.
}

The estimator of the ATT is given as:

$$
\delta^{\mathrm{ATT}}=\frac{1}{N_{1}} \sum_{i: Z=1}^{N_{1}}\left[Y_{i}(1)-\widehat{Y}_{i}(0)\right]
$$

where: $N_{1}$ is the number of units in the treated group, $Y_{i}(1)$ is the observed outcome for the $i$-th treated unit, and $\hat{Y}_{i}(0)$ is the estimated counterfactual outcome for the same unit. The counterfactual outcome for the $i$-th treated unit is obtained as the average of the outcome variables for all matched units in the control group of the $i$-th treated unit. Formally:

$$
\widehat{Y}_{i}(0)=\frac{1}{\# J_{M}(i)} \sum_{m \in J_{M}(i)} Y_{m}(0)
$$

where $M$ is the predetermined number of matches and $J_{M}(i)=\{j$ : unit $j$ belongs to the group of the $M$ nearest neighbors to unit $i$ \} the index 
set of matches for each treated unit $i=1, \ldots, N$. Since the quality of matching decreases when the number of matches increases, the value of $M$ should be small (Abadie \& Imbens, 2002). The matching procedure implemented in this paper uses a 1-to-3 matching (i.e., $M=3$ ) with replacement where each subsidized hotel is compared with a fictitious hotel built as the average of three unsubsidized hotels.

The above matching model, however, does not ensure that unobservable hotel characteristics do not bias the estimation, i.e., systematic differences between subsidized and unsubsidized outcomes may persist. For instance, the managerial ability of the owner of the hotels can affect the quality of the matches and bias the ATT estimation. Hence, to control for such unobserved and time-invariant differences in outcomes between the treated and non-treated hotels, it is possible to extend the cross-sectional matching estimator by implementing a conditional difference-in-differences matching estimator (CDiD) (Smith \& Todd, 2005) to estimate the ATT. In the CDiD approach, after each treated hotel is matched with one or more control hotels that are similar in terms of a set of predetermined and observable characteristics, all the variables included in the analysis are expressed as before-after treatment differences. This allows for washing away all unobserved and time-invariant differences between treated and untreated that are correlated with outcomes. Formally, for the matched treated and control observations, the adopted CDiD matching estimator is as follows (Smith \& Todd, 2005):

$$
\begin{aligned}
\widehat{\delta}^{\mathrm{CDiD}}=\frac{1}{N_{1}} \sum_{i \in I_{1}} & \left\{\left[Y_{t 1, i}(1)-Y_{t 0, i}(0)\right]\right. \\
& \left.-\sum_{j \in I_{0}} W_{i j}\left[Y_{t 1, j}(0)-Y_{t 0, j}(0)\right]\right\}
\end{aligned}
$$

where $N_{1}$ is the number of treated firms, $Y_{t 0, i}$, and $Y_{t 1, i}$, are the values of the outcome variable, respectively, before and after the treatment of a firm $i$ in the treated group $\left(I_{1}\right)$, and $Y_{t 0, j}$, and $Y_{t 1, j}$, are the values of the objective variable, respectively, before and after the treatment of a firm $j$ in the control group $\left(I_{0}\right) ; W_{i j}$ represents the weights and depends on the particular cross-sectional matching estimator employed, which in our case, is the multivariate matching estimator developed by Abadie and Imbens (2002).

\subsection{Variables selection}

To implement the estimation procedure, it was necessary first to select the performance variables, and second to choose the hotels characteristics used for the matching procedure (matching variables).

As described in Section 3, subsidies to investment were expected to influence several dimensions of performance. Labor productivity (Hypothesis 1a) was measured as the ratio of revenue to total employment (lab_prod). To test Hypothesis $1 \mathrm{~b}$, we considered: a) the occupancy rate (occ_rate), defined as the ratio of total guest nights spent in a year to the number of beds available, divided by the number of days the hotel was operative; and b) the revenue per available room (revpar), obtained as the ratio of the (deflated) yearly revenue to the number of rooms divided by the number of days the hotel was operative. Finally, to account for the possible effect of subsidies on seasonality as stated in Hypothesis 1c, a measure of variability in the level of activity over time (occ_var), defined as the coefficient of variation in the number of monthly arrivals over a year, was used.

The proper matching variables must be identified among hotel characteristics that are likely to influence the propensity of hotels to apply for public grants and affect hotel performance, but are not af- fected by the subsidy. To guarantee these conditions, hotel characteristics in a pre-treatment period were identified. Specifically, the following hotel characteristics were considered ${ }^{3}$ : (a) the legal form; (b) the hotel size; (c) the hotel category; (d) the level of external services; (e) the international attractiveness; (f) the capital intensity; (g) a set location variables. A more detailed description of the construction of matching variables follows.

The legal form, i.e., whether a hotel is a sole proprietorship, partnership, or a limited liability company, can influence the possibility of applying for public subsidization programs (Almus \& Czarnitzki, 2003). In fact, limited liability owners bear risk up to a certain amount, and thus have greater incentive to pursue riskier projects. The categorical variable legal form, which classifies hotels by sole proprietorship, partnership, and limited liability forms, accounts for the different legal forms.

Different amounts of subsidization and different performance levels may depend on firm size. Firm size is a useful predictor of financial constraints (Hadlock \& Pierce, 2010). Although the focus of the analysis was on small hotels, a finer control for hotel size was considered. In accordance with the literature on hotels, the number of available rooms as a proxy for hotel size (size) was used.

The hotel category summarizes the amount and complexity of services provided in a hotel. Higher categories offer a wider range of services and require special equipment and organization. Moreover, a hotel's category is strictly related to the "type" of hotelier. A survey from the local statistical office (see PAT Servizio Statistica, 2006) distinguished hoteliers with respect to their entrepreneurial attitude toward hotel management, showing a strict correlation between the entrepreneurial attitude and the hotel category. Only $7-12 \%$ of active entrepreneurs belong to one- and two-star categories, while only $8-12 \%$ of passive entrepreneurs belong to three- and four-star categories. A cross-comparison between these categories can help explain important components of the unobserved differences in entrepreneurial behaviors and hotel performance. In this study, a binary variable (cat) is defined, taking value "high" for three- and four-star hotels, and "low" for one- and two-star hotels. Differences in firms' behavior and performance due to the different levels of external services used by the hotels in running their activities were also accounted for. To this aim, the level of external services (serv) was defined as the ratio of services' cost to total revenue.

Hotels that are attractive to international tourists are expected to be more efficiently managed (Assaf \& Knežević Cvelbar, 2011). Greater exposure to foreign markets increases their opportunity to gain external knowledge or to generate new knowledge from international tourist encounters, which eventually impact on hotel performance. A high percentage of international sales may also be an indirect measure of quality of management and employees, as hosting foreign customers commonly requires higher skills and competency levels (e.g., knowledge of foreign languages). Hotels open to foreign markets may be more interested in restructuring and improving their equipment and facilities than hotels predominantly operating in domestic markets. The international attractiveness (int) of hotels was measured as the ratio of the number of nights spent by foreign guests to the total number of nights over a year.

\footnotetext{
3 The main concept to follow when selecting matching variables is that there are no unobserved differences between treated and control units after conditioning observed covariates (Stuart, 2010). Accordingly, it should be necessary to include all variables related to both the treatment assignment and the outcome. There are, however, "both reasons for and against including all of the reasonable matching covariates available" (Caliendo \& Kopeinig, 2008, p. 39), and the choice should be undertaken with reference to theory and previous empirical findings.
} 
Firms with low capital intensity are expected to have smaller operating leverage and therefore a smaller volatility of earnings, given similar demand fluctuations, than firms with higher capital intensity (Baginski, Lorek, Willinger, \& Branson, 1999; Lev, 1983). A proxy of capital intensity (cap) is defined as the ratio of amortization of tangible capital to revenue (Asthana \& Zhang, 2006; Baginski et al., 1999; Cheng, 2005).

The role of destination is taken into account. The link between location and firm performance is relevant in services where demand is spatially variable (Morikawa, 2011). Therefore, we introduced a set of dummy variables (dest) to control for cross-sectional heterogeneity among destinations. Finally, the fine-grained effects of unevenly distributed spatial demand densities were considered. It is reasonable to consider that the proximity to physical and natural amenities affects the attractiveness of hotels. A market-potential function (Harris, 1954) was introduced to measure hotels' proximity to attraction points (prox) under the assumption that the impact of attraction points tends to decrease the greater the distance from the hotel. The attraction points considered are ski areas, lakes, and well-known beauty spots. A measure of market potential was defined as a decreasing function of the distance from the attraction points of interest, as follows:

$$
\operatorname{prox}_{i}=\sum_{j=1, \ldots, n}\left(d_{i j}\right)^{-1}
$$

where $d_{i j}$ is the (Euclidean) distance between a hotel $i$ and an attraction point $j, j=1, \ldots, n$. Moreover, hotels may benefit from positive externalities accruing from agglomeration economies (Baum \& Haveman, 1997; Baum \& Mezias, 1992; Chung \& Kalnins, 2001; Kalnins \& Chung, 2004). Moreover, co-location may provide opportunities for frequent interactions and exchanges of information among hotel managers (Gan \& Hernandez, 2013). As a consequence, co-location may activate imitative behavior in the decision to apply for subsidies. Co-location effects are controlled using the index (co-loc), which is a decreasing function of a hotel's distance from all other ho- tels (as in the case of the prox variable):

$$
c o-\operatorname{loc}_{i}=\sum_{j=1, \ldots, m}\left(q_{i j}\right)^{-1}
$$

where $q_{i j}$ is the (Euclidean) distance between a hotel $i$ and a hotel $j$, $j=1, \ldots, m$.

As shown in Table 1, variables of interest for the treated and non-treated hotels, before matching, are rather different. Differences between the treated and non-treated groups were found both for some of the objective variables (occ_rate and revpar) and for covariates (cap, size, co-loc, cat, legal_form), suggesting the need for the matching protocol we used.

\section{Results}

This section first presents evidence to support the validity of the estimation strategy used and then reports the main findings of the analysis.

To identify causal effects in the CDiD strategy, treated and control units should be similar, except for their treatment statuses. Although the identifying restriction of the CDiD is not directly testable, observing no difference in changes of outcome before treatment periods, given the observable hotel characteristics, provides an indirect test of unconfoundedness and supports the validity of the empirical CDiD strategy (Imbens, 2004). Table 2 shows the results of this indirect test. Variations in the outcomes both one and two years before the treatment are considered: no differences between performance indicators for subsidized and unsubsidized hotels are statistically significant at the $5 \%$ level. That is, once matched, the two groups are ex-ante similar in all respects.

The results of the analysis are shown in Table 3, which contains the estimates of the average treatment effect on treated hotels $\left(\delta^{\mathrm{CDiD}}\right)$, obtained using the conditional difference-in-difference estimator.

Moving to the substantial results, first, receiving subsidies was found to have a positive, persistent, and statistically significant effect

Table 1

\begin{tabular}{|c|c|c|c|c|c|c|c|c|}
\hline \multirow[t]{2}{*}{ Variable } & \multirow[t]{2}{*}{ Diff. between treated and non-treated } & \multirow[t]{2}{*}{$p$-value } & \multicolumn{3}{|c|}{ Treated hotels } & \multicolumn{3}{|c|}{ Non-treated hotels } \\
\hline & & & $N$ & Mean & Std. Dev. & $N$ & Mean & Std. Dev. \\
\hline \multicolumn{9}{|l|}{ Outcomes } \\
\hline occ_rate & 0.032 & 0.003 & 154 & 0.329 & 0.129 & 1488 & 0.296 & 0.134 \\
\hline occ_var & -0.009 & 0.742 & 154 & 0.932 & 0.351 & 1488 & 0.942 & 0.359 \\
\hline revpar & 2.277 & 0.037 & 154 & 23.018 & 12.638 & 1488 & 20.740 & 14.245 \\
\hline lab_prod & 59.192 & 0.962 & 154 & 41078.2 & 13703.7 & 1488 & 41019.0 & 21699.5 \\
\hline \multicolumn{9}{|l|}{ Cov. (continuous) } \\
\hline int & -0.024 & 0.242 & 154 & 0.249 & 0.246 & 1488 & 0.273 & 0.260 \\
\hline cap & 0.031 & 0.000 & 154 & 0.174 & 0.105 & 1488 & 0.142 & 0.124 \\
\hline size & 3.014 & 0.028 & 154 & 31.78 & 15.89 & 1488 & 28.77 & 18.06 \\
\hline co-loc & -1203.6 & 0.005 & 154 & 542.05 & 3880.8 & 1488 & 1745.6 & 11631.8 \\
\hline prox & -0.0014 & 0.800 & 154 & 0.0126 & 0.0078 & 1488 & 0.0127 & 0.0078 \\
\hline serv & -0.0017 & 0.916 & 154 & 0.216 & 0151 & 1488 & 0.215 & 0.005 \\
\hline \multicolumn{9}{|l|}{ Cov. (discrete $\left.{ }^{\mathrm{a}}\right)$} \\
\hline cat & 0.097 & 0.017 & 154 & 0.721 & & 1488 & 0.623 & \\
\hline legal_form 1 & -0.107 & 0.003 & 154 & 0.143 & & 1488 & 0.250 & \\
\hline legal form 2 & 0.111 & 0.006 & 154 & 0.753 & & 1488 & 0.641 & \\
\hline legal_form 3 & -0.004 & 0.870 & 154 & 0.104 & & 1488 & 0.108 & \\
\hline
\end{tabular}

Characteristics and outcomes for treated and non-treated hotels 1 year before treatment (not matched samples).

Note: data are pooled across years.

a Only mean values are reported.

$p<0.05$.

$p<0.01$. 
Table 2

Over-identification test.

\begin{tabular}{lllll}
\hline Outcome & $\delta^{\text {CDiD }}$ & Std. Err. & z-stat & $p$-value \\
\hline occ_rate & -0.002 & 0.007 & -0.220 & 0.828 \\
occ_var & 0.032 & 0.019 & 1.740 & 0.082 \\
revpar & -0.249 & 0.467 & -0.530 & 0.594 \\
lab_prod & 965.2 & 1358.0 & 0.710 & 0.477 \\
\hline
\end{tabular}

Note: Estimates are given as the difference in levels between treated and control hotels; Exact match on hotel category, destination, and year.

on all outcomes considered. The effect of public subsidies on labor productivity (lab prod) was high and increased over time, thus supporting Hypothesis 1a. The daily occupancy rate (occ_rate) of subsidized hotels increased on average by about $1.6 \%$ after one year, and by roughly $3.5 \%$ after two years. Moreover, the average effect on daily revenue per available rooms (revpar) was also positive and increased over time, consistently with Hypothesis 1b. Finally, Hypothesis 1c was supported, as there was a reduction in the variability of demand (occ_var) one year and two years after the subsidy.

The question of whether the attractiveness of destinations moderates the effects of public subsidies for investments is then addressed. Table 4 shows the estimates of the treatment effect, separately for hotels located in more or less attractive areas, where the attractiveness of each municipality is measured by the ratio of the total average nights spent by tourists in hotels located within a municipality and the residential population of the municipality. A municipality is defined as highly (low) attractive if this ratio is higher than the median value across all municipalities within the region

In less attractive areas, the effect of public subsidies on occ_var and revpar is weaker. The effect on occ rate is weaker at the limits of statistical significance $(p=0.093)$ and vanishes after two years. Finally, no effect is observable on lab_prod. In sum, there was support for Hypothesis 2 of a moderating effect of destination attractiveness.
The direction of the effect is also empirically established, as a reinforcement of the effect of public subsidies in more attractive destinations was observed.

Table 5 summarizes the hypotheses and the results of their testing.

\section{Discussion}

The renewal of physical capital plays an important role in raising the productivity and competitiveness of tourism firms by providing new equipment and infrastructure and facilitating the introduction of new technology (Blake et al., 2006). Governments often play a role by stimulating and supporting this process (Bernini \& Pellegrini, 2013; OECD, 2010). This paper extends the literature on the effectiveness of public intervention in tourism by analyzing a subsidization policy directed toward supporting the physical renovation of micro and small hotels in a regional context.

The results have implications for management and policymakers.

There is clear evidence of the effectiveness of public subsidies directed toward promoting the investments of micro and small hotels. Capital subsidies are generally designed to solve market failure in the credit market. Small firms generally must cope with limited internal resources and have higher constraints than large firms in obtaining financial capital or credit to finance investments (Carreira \& Silva, 2010; Wanhill, 2000). This means that micro and small firms might benefit more from public subsidies than larger ones. Previous studies found that for medium and large tourism firms, the availability of public capital subsidies led to investments with less-than-average productivity potential (Bernini \& Pellegrini, 2013). However, the results in this paper show a positive and significant effect of subsidies on productivity as well as on revenue and demand management of micro and small hotels.

This has an important consequence for hotels management. The ability to successfully gain access to external resources by applying

Table 3

Estimates of the ATT.

\begin{tabular}{|c|c|c|c|c|c|c|c|c|}
\hline \multirow[t]{2}{*}{ Outcome } & \multicolumn{3}{|c|}{ After one year } & 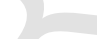 & \multicolumn{4}{|c|}{ After two years } \\
\hline & $\delta^{\mathrm{CDiD}}$ & Std. Err. & z-stat & $p$-value & $\delta^{\mathrm{CDiD}}$ & Std. Err. & z-stat & $p$-value \\
\hline occ_rate & 0.016 & 0.008 & 2.170 & 0.030 & 0.035 & 0.012 & 2.890 & 0.004 \\
\hline occ_var & -0.094 & 0.027 & -3.470 & 0.001 & -0.106 & 0.037 & -2.880 & 0.004 \\
\hline revpar & 2.556 & 0.647 & 3.950 & 0.000 & 4.325 & 1.064 & 4.060 & 0.000 \\
\hline lab_prod & 4563.7 & 1733.0 & 2.630 & 0.009 & 6911.0 & 2324.3 & 2.970 & 0.003 \\
\hline
\end{tabular}

Note: Estimates are given as the difference in levels between treated and control hotels; Exact match on hotel category, destination and year; \% of exact matches: 100.

$$
\begin{gathered}
p<0.05 . \\
p<0.01 .
\end{gathered}
$$

Table 4

\begin{tabular}{|c|c|c|c|c|c|c|c|c|c|}
\hline \multirow[t]{2}{*}{ Attractiveness of the area } & \multirow[t]{2}{*}{ Outcome } & \multicolumn{4}{|c|}{ After one year } & \multicolumn{4}{|c|}{ After two years } \\
\hline & & $\delta^{\mathrm{CDiD}}$ & Std. Err. & z-stat & $p$-value & $\delta^{\mathrm{CDiD}}$ & Std. Err. & z-stat & $p$-value \\
\hline \multirow[t]{4}{*}{ high } & occ_rate & 0.032 & 0.009 & 3.460 & 0.001 & 0.048 & 0.016 & 3.020 & 0.003 \\
\hline & occ_var & -0.087 & 0.030 & -2.880 & 0.004 & -0.118 & 0.048 & -2.490 & 0.013 \\
\hline & revpar & 3.151 & 1.014 & 3.110 & 0.002 & 5.790 & 1.663 & 3.480 & 0.001 \\
\hline & lab_prod & 7239.4 & 2098.1 & 3.450 & 0.001 & 9475.7 & 2808.4 & 3.370 & 0.001 \\
\hline \multirow[t]{4}{*}{ low } & occ_rate & 0.021 & 0.012 & 1.680 & 0.093 & 0.018 & 0.018 & 0.970 & 0.332 \\
\hline & occ_var & -0.081 & 0.033 & -2.440 & 0.015 & -0.081 & 0.043 & -1.890 & 0.058 \\
\hline & revpar & 2.618 & 0.914 & 2.860 & 0.004 & 2.347 & 1.125 & 2.090 & 0.037 \\
\hline & lab_prod & -815.8 & 3961.6 & -0.210 & 0.837 & -259.5 & 3249.2 & -0.080 & 0.936 \\
\hline
\end{tabular}

Estimates of the ATT by the rate of attractiveness of the area

Note: Estimates are given as the difference in levels between treated and control hotels; Exact match on hotel category, destination, and year; \% of exact matches: 100. 
Table 5

Summary of the hypotheses outcomes.

\begin{tabular}{ll}
\hline Hypothesis & Results \\
\hline $\begin{array}{l}\text { Hypothesis 1a A public subsidy for hotel investment induces an } \\
\text { increase in the labor productivity in subsidized hotels. }\end{array}$ & Supported \\
$\begin{array}{l}\text { Hypothesis 1b A public subsidy for hotel investment induces an } \\
\text { increase in the profitability and occupancy in subsidized hotels. }\end{array}$ & Supported \\
$\begin{array}{l}\text { Hypothesis 1c A public subsidy to investment allows better demand } \\
\text { management in subsidized hotels. }\end{array}$ & Supported \\
$\begin{array}{l}\text { Hypothesis 2 For a hotel, the effect of receiving a subsidy is moderated } \\
\text { (positively or negatively) by the attractiveness of the destination. }\end{array}$ & Supported \\
\hline
\end{tabular}

for public subsidies should be a crucial distinctive capability for small hotels. The innovation activity of hotels has technological and non-technological components that are intertwined and play a crucial role in the economic performance of hotels (Den Hertog, Gallouj, \& Segers, 2011; Orfila-Sintes \& Mattsson, 2009). While non-technological innovation (e.g., business model innovation) is mainly developed internally, technological innovation in the sector is largely embodied in machinery, equipment, and facilities acquired by hotels from external sources (Blake et al., 2006; Mattsson \& OrfilaSintes, 2014; Orfila-Sintes et al., 2005). In this respect, the availability of public financial resources allows micro and small hotels to accede to the external sources of innovation and to not delay or even renounce to adopt and maintain the standards required for high-quality and sustainable tourism.

A second consequence is that the benefits stemming from the policy may be not only for the economic performance of subsidized hotels, but also for the entire destination. The upgrading of hotels in terms of the category and quality of service delivered can capture consumers willing to travel in the off-peak seasons and, therefore, reduce the yearly variability of demand in the destination, balancing the rate of use of all hotel facilities (Parrilla, Font, \& Nadal, 2007). The effect of subsidies on smoothing hotels' demand fluctuations is, in this respect, particularly worth noting. The physical renovation of hotel facilities is thus confirmed to be an effective strategy for destinations to meet the needs of customers (Medina-Muñoz, Medina-Muñoz, \& Sánchez-Medina, 2016) and to increase the competitiveness and sustainability of destinations.

One of the most important findings involves the absence of evidence in favor of the hypothesis that public subsidies activate a catching up of less-attractive areas. Not only there is no evidence of a catch-up effect, but subsidies increase the divide between high- and low-demand areas. This is a clear suggestion that demand is a fundamental moderator in the relationship between subsidies and performance. In general, it can be argued, following Lazzarini (2015), that the development of a competitive advantage in less-attractive areas requires a combination of complementary actions building on geographical specificity. The observation of complementarity between investment decisions and demand management has important consequences both for hotel management and the design of public policies. From the point of view of management, it must be considered that the outcome of an investment decision is conditioned by destination policies enacted by several subjects. While investment decisions are controlled by the hotel owner, in small mountain communities, destination management results from a co-operative effort. The coordination of hotel owners' decisions with destination communities' policies is a delicate issue that must be addressed to move toward a win-win strategy (Boyd \& Singh, 2003). For instance, middle mountain resorts should take advantage of the promotion of their destinations as resorts dedicated to cross country skiing and mountain biking. However, promoting a new image or addressing new segments of demand is not simply a matter of investments in hotel facilities, but depends on building a destination image and the development of a community attitude toward the natural environment.

The same public policy can foster the co-ordination of holders of complementary resources. The destination product can be conceived as a bundle of services and goods demanded by tourists and supplied by different firms operating in a destination, each one producing part of the final product (Alvarez-Albelo \& Hernandez-Martin, 2012; Andergassen, Candela, \& Figini, 2013). Accordingly, the success of a destination and the success of individual firms are intertwined (Beritelli, Bieger, \& Laesser, 2007; Haugland, Ness, Grønseth, \& Aarstad, 2011). In this light, a well-designed incentive scheme can help focalize the behavior of different subjects toward a common goal.

A possible public goal in the future could be to help coordinate investment decisions for weaker destinations to improve hotels quality or address new segments of demand. This is an important issue among tourist destinations today, as global warming is affecting snowfall. Resorts affected by the reduction in snowfall have had to reposition their promotional offers toward attractions other than alpine skiing.

Further research can help to overcome some limitations of the present study. The time span of the analysis results from empirical considerations and the need to avoid the effect of common shocks. A longer time span will improve the analysis of the persistence of the observed effects. In the context of manufacturing firms, Bronzini and De Blasio (2006), for instance, found decreasing effects five years after the receipt of a subsidy. Future researchers should consider extending the time period of analysis to understand whether similar patterns take place in the hotel industry. Moreover, a pre- and post-crisis comparison would help to understand whether the crisis impacted investment decisions and on their economic consequences.

An issue open to debate involves the external validity of the analysis, which depended on specific local conditions and the particular economic structure of a given setting. While the authors are confident that similar results can be obtained in similar entrepreneurial environments, such as those in the Alpine area and mountain resorts, it is unclear whether underinvestment and the need for public subsidy is also a problem in settings where large chains and limited liability companies prevail. For this reason, the authors are cautious of normatively extending results to other local contexts, where small family hotels do not prevail.

\section{Conclusions}

The paper provides new evidence on the effectiveness of public subsidies for the hotel industry. The empirical domain of analysis in this study was the hotel industry in the Trentino province in Italy. The study investigated the local government's ability to enhance the quality of micro and small hotel investments by co-financing fixed capital and enhancing sustainability investments. The study also offered some insights into the role of agglomeration and localization factors in determining the magnitude of the effect of a policy. The causal effect of the subsidization policy can be granted due to the high degree of comparability that is possible to find in local contexts such as the one analyzed. Moreover, the context allowed confounding effects arising from the overlapping of policies to be avoided, given that hotels in Trentino can only apply for regional subsidies. The available data enabled the investigation of the effects of subsidization on the occupancy rate, variability of the occupancy rate over time, revenues per available room, and labor productivity. The results show that subsidized hotels have, on average, a higher and less variable occupancy 
rate over the span of a year. As a consequence of investments, hotels also increase their revenue per available room and labor productivity. This study has shown that these effects are persistent and increase over a two-year time window following the treatment. Finally, we have found the effects of public subsidies to be uneven across tourist destinations with different levels of attractiveness.

Finally, an interesting future development would be to disentangle the effect of different types of investments, particularly investments devoted to facility improvements, from investments in new facilities or environmental sustainability.

\section{Acknowledgements}

This work was developed within the research project "Analisi della produttività nel settore alberghiero: fattori manageriali e ruolo delle politiche pubbliche" which was financed by the Fondazione Cassa di Risparmio di Trento e Rovereto. The APIAE and ISPAT are here acknowledged for providing access to the data.

\section{References}

Abadie, A., Imbens, G.W., 2002. Simple and bias-corrected matching estimators for average treatment effects. In: NBER Working Paper n. 283.

Almus, M., Czarnitzki, D., 2003. The effects of public R\&D subsidies on firms' innovation activities: The case of Eastern Germany. Journal of Business \& Economic Statistics 21 (2), 226-236.

Alvarez-Albelo, A.D., Hernandez-Martin, R., 2012. Congestion and coordination problems in a tourism economy. Tourism Economics 18 (4), 691-710.

Andergassen, R., Candela, G., Figini, P., 2013. An economic model for tourism destinations: Product sophistication and price coordination. Tourism Management 37, 86-98.

Andraz, J.M., Norte, N.M., Gonçalves, H.S., 2015. Effects of tourism on regional asymmetries: Empirical evidence for Portugal. Tourism Management 50, 257-267.

Assaf, A., Knežević Cvelbar, L., 2011. Privatization, market competition, international attractiveness, management tenure, and hotel performance: Evidence from Slovenia. International Journal of Hospitality Management 30 (2), 391-397.

Asthana, S.C., Zhang, Y., 2006. Effect of R\&D investments on persistence of abnormal earnings. Review of Accounting and Finance 5 (2), 124-139.

Baginski, S.P., Lorek, K.S., Willinger, G.L., Branson, B.C., 1999. The relationship between economic characteristics and alternative annual earnings persistence measures. The Accounting Review 74 (1), 105-120.

Balaguer, J., Cantavella-Jorda, M., 2002. Tourism as a long-run economic growth factor: The Spanish case. Applied Economics 34 (7), 877-884.

Barca, F., McCann, P., Rodríguez-Pose, A., 2012. The case for regional development intervention: Place-based versus Place-neutral approaches. Journal of Regional Science 52 (1), 134-152.

Baum, J.A.C., Mezias, S.J., 1992. Localized competition and organizational failure in the Manhattan hotel industry. Administrative Science Quarterly 37, 580-604.

Baum, J.A., Haveman, H.A., 1997. Love thy neighbor? Differentiation and agglomeration in the Manhattan hotel industry, 1898-1990. Administrative Science Quarterly 42 (2), 304-338.

Baum, T., Hagen, L., 1999. Responses to seasonality: The experiences of peripheral destinations. International Journal of Tourism Research 1 (5), 299-312.

Beritelli, P., Bieger, T., Laesser, C., 2007. Destination governance: using corporate governance theories as a foundation for effective destination management. Journal of Travel Research 46 (1), 96-107.

Bernini, C., Pellegrini, G., 2013. Is subsidizing tourism firms an effective use of public funds?. Tourism Management 35, 156-167.

Bigné, J.E., Sánchez, M.I., Sánchez, J., 2001. Tourism image, evaluation variables and after purchase behavior: Inter-relationship. Tourism Management 22, 607-616.

Blake, A., Sinclair, M.T., Soria, J.A.C., 2006. Tourism productivity: Evidence from the United Kingdom. Annals of Tourism Research 33 (4), 1099-1120.

Borodako, K., Rudnicki, M., 2014. Transport accessibility in business travel: A case study of central and east European cities. International Journal of Tourism Research 16, 137-145

Boyd, S.W., Singh, S., 2003. Destination communities: Structures, resources and types. In: Singh, S., Timothy, D.J., Dowling, R.K. (Eds.), Tourism in destination communities. CABI Publishing, Wallingford UK (Ch. 2).

Brida, J.G., Giuliani, D., 2013. Empirical assessment of the tourism-led growth hypothesis: The case of the Tirol-Südtirol-Trentino Europaregion. Tourism Economics 19 (4), 745-760.

Bronzini, R., de Blasio, G., 2006. Evaluating the impact of investment incentives: The case of Italy's Law 488/1992. Journal of Urban Economics 60 (2), 327-349.
Buigues, P.A., Sekkat, K., 2011. Public subsidies to business: An international comparison. Journal of industry, competition and trade 11 (1), 1-24.

Caliendo, M., Kopeinig, S., 2008. Some practical guidance for the implementation of propensity score matching. Journal of Economic Surveys 22 (1), 31-72.

Cheng, Q., 2005. What determines residual income?. The Accounting Review 80 (1), $85-112$.

Choi, T.Y., Chu, R.K.S., 1999. Consumer perceptions of the quality of services in three hotel categories in Hong Kong. Journal of Vacation Marketing 5 (2), $176-189$.

Chung, W., Kalnins, A., 2001. Agglomeration effects and performance: A test of the Texas lodging industry. Strategic Management Journal 22 (10), 969-988.

Cocklin, C., Harte, M., Hay, J., 1990. Resource assessment for recreation and tourism: A New Zealand example. Landscape and Urban Planning 19 (3), 291-303.

Corsino, M., Mirabella, C., Tundis, E., Zaninotto, E., 2011. Fattori manageriali, condizioni di contesto ed efficienza produttiva nei servizi. Uno studio sul settore alberghiero in Trentino. Economia dei Servizi 1, 11-28.

Croes, R.R., Severt, D.E., 2007. Evaluating short-term tourism economic effects in confined economics - Conceptual and empirical considerations. Tourism Economics 13 (2), 289-307.

Den Hertog, P., Gallouj, F., Segers, J., 2011. Measuring innovation in a 'low-tech' service industry: The case of the Dutch hospitality industry. The Service Industries Journal 31 (9), 1429-1449.

Estol, J., Font, X., 2016. European tourism policy: Its evolution and structure. Tourism Management 52, 230-241.

Fleischer, A., Felsenstein, D., 2004. Short-run output and employment effects arising from assistance to tourism SMEs: Evidence from Israel. In: Thomas, R. (Ed.), Small firms in tourism: International perspectives. Elsevier Science, UK, pp. 71-82.

Gabriele, R., Tundis, E., Zaninotto, E., 2016. Are subsidies to hotel investment an effective tool to enhance regional tourism? A firm level analysis. e-Review of Tourism Research (in press).

Gan, L., Hernandez, M.A., 2013. Making friends with your neighbors? Agglomeration and tacit collusion in the lodging industry. The Review of Economics and Statistics 95 (3), 1002-1017.

Hadlock, C.J., Pierce, J.R., 2010. New evidence on measuring financial constraints: Moving beyond the KZ index. Review of Financial Studies 23 (5), 1909-1940.

Harris, C.D., 1954. The market as a factor in the localization of industry in the United States. Annals of the Association of American Geographers 44 (4), 315-348.

Hassanien, A., Baum, T., 2002. Hotel innovation through property renovation. International Journal of Hospitality \& Tourism Administration 3 (4), 5-24.

Haugland, S.A., Ness, H., Grønseth, B.O., Aarstad, J., 2011. Development of tourism destinations: An integrated multilevel perspective. Annals of Tourism Research 38 (1), 268-290.

Hipp, C., Grupp, H., 2005. Innovation in the service sector: The demand for service-specific innovation measurement concepts and typologies. Research Policy 34 (4), 517-535.

Hjalager, A.M., 2010. A review of innovation research in tourism. Tourism Management $31(1), 1-12$.

Imbens, G.W., 2004. Nonparametric estimation of average treatment effects under exogeneity: A review. The Review of Economics and Statistics 86 (1), 4-29.

Israeli, A., 2002. Star rating and corporate affiliation: Their influence on room price and performance of hotels in Israel. International Journal of Hospitality Management 21, 405-424.

Kalnins, A., Chung, W., 2004. Resource-seeking agglomeration: A study of market entry in the lodging industry. Strategic Management Journal 25 (7), 689-699.

Kashyap, R., Bojanic, D.C., 2000. A structural analysis of value, quality, and price perceptions of business and leisure travelers. Journal of Travel Research 39 (1), $45-51$.

King, G., Nielsen, R., 2016. Why propensity scores should not be used for matching. Retrieved from http://gking.harvard.edu/files/gking/files/psnot.pdf.

Lazzarini, S.G., 2015. Strategizing by the government: Can industrial policy create firm-level competitive advantage?. Strategic Management Journal 36 (1), 97-112.

Lee, C.C., Chang, C.P., 2008. Tourism development and economic growth: A closer look at panels. Tourism Management 29 (1), 180-192.

Lev, B., 1983. Some economic determinants of time-series properties of earnings. Journal of Accounting and Economics 5, 31-48.

Logar, I., 2010. Sustainable tourism management in Crikvenica, Croatia: An assessment of policy instruments. Tourism Management 31 (1), 125-135.

Mattsson, J., OrfilaSintes, F., 2014. Hotel innovation and its effect on business performance. International Journal of Tourism Research 16 (4), 388-398.

Medina-Muñoz, D.R., Medina-Muñoz, R.D., Sánchez-Medina, A.J., 2016. Renovation strategies for accommodation at mature destinations: A tourist demand-based approach. International Journal of Hospitality Management 54, 127-138.

Molina-Azorin, J.F., Pereira-Moliner, J., Claver-Cortés, E., 2010. The importance of the firm and destination effects to explain firm performance. Tourism Management 31 (1), 22-28.

Morikawa, M., 2011. Economies of density and productivity in service industries: An analysis of personal service industries based on establishment-level data. The Review of Economics and Statistics 93 (1), 179-192. 
Neumark, D., Simpson, H., 2014. Place-based policies. In: NBER Working Paper no 20049.

OECD, 2010. OECD Tourism Trends and Policies 2010. OECD Publishing, Paris. OECD, 2014. OECD Tourism Trends and Policies 2014. OECD Publishing, Paris. Orfila-Sintes, F., Crespí-Cladera, R., Martínez-Ros, E., 2005. Innovation activity in the hotel industry: Evidence from Balearic Islands. Tourism Management 26 (6), $851-865$.

Orfila-Sintes, F., Mattsson, J., 2009. Innovation behavior in the hotel industry. Omega 37 (2), 380-394.

Paci, R., Marrocu, E., 2014. Tourism and regional growth in Europe. Papers in Regional Science 93 (S1), S25-S50.

Parrilla, J.C., Font, A.R., Nadal, J.R., 2007. Accommodation determinants of seasonal patterns. Annals of Tourism Research 34 (2), 422-436.

Pikkemaat, B., 2008. Innovation in small and medium-sized tourism enterprises in Tyrol, Austria. The International Journal of Entrepreneurship and Innovation 9 (3), 187-197.

Rubin, D., 1986. Statistics and causal I = inference: Which ifs have causal answers. Journal of the American Statistical Association 81 (396), 961-962.

Rubin, D.B., 1977. Assignment to treatment group on the basis of covariate. Journal of Educational Statistics 2, 1-26.

Schubert, S.F., Brida, J.G., 2008. Dynamic effects of subsidizing the tourism sector Tourism Economics 14 (1), 57-80.

Servizio Statistica, P.A.T., 2006. L'imprenditoria alberghiera nella provincia di Trento. Provincia Autonoma di Trento, Trento.

Sheldon, P.J., 1983. The impact of technology on the hotel industry. Tourism Management 4 (4), 269-278.

Sirilli, G., Evangelista, R., 1998. Technological innovation in services and manufacturing: Results from Italian surveys. Research Policy 27 (9), 881-899.

Smith, J.A., Todd, P.E., 2005. Does matching overcome LaLonde's critique of nonexperimental estimators?. Journal of Econometrics 125 (1), 305-353.

Stuart, E.A., 2010. Matching methods for causal inference: A review and a look forward. Statistical Science 25 (1), 1-21.

Sundbo, J., Orfila-Sintes, F., Sørensen, F., 2007. The innovative behavior of tourism firms - Comparative studies of Denmark and Spain. Research Policy 36 (1), 88-106.

Thomas, R., 1994. European union enterprise policy and the hospitality industry. International Journal of Contemporary Hospitality Management 6 (4), 10-15.

Thomas, R., Shaw, G., Page, S.J., 2011. Understanding small firms in tourism: A perspective on research trends and challenges. Tourism Management 32 (5), 963-976.

Wanhill, S., 2000. Small and medium tourism enterprises. Annals of Tourism Research 27 (1), 132-147.

Weiermair, K., 2006. Product improvement or innovation: What is the key to success in tourism? In: OECD (Ed.), Innovation and growth in tourism. OECD, Paris, pp. 53-69.

World Trade Organization, 2006. World trade report. Exploring the links between subsidies, trade, and the WTO. WTO, Geneva.

Yang, Z., Cai, J., 2016. Do regional factors matter? Determinants of hotel industry performance in China. Tourism Management 52, 242-253.

Zúñiga-Vicente, , Alonso-Borrego, C., Forcadell, F.J., Galán, J.I., 2014. Assessing the effect of public subsidies on firm R\&D investment: A survey. Journal of Economic Surveys 28 (1), 36-67.

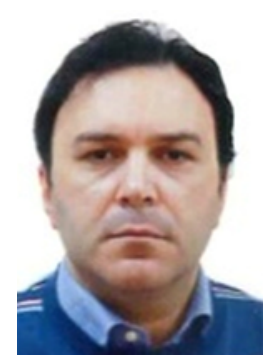

Enrico Tundis is Research Fellow at the Department of Economics and Management, University of Trento, Italy and ISPAT, Trento,
Italy. He holds a master degree in Management Engineering (University of Calabria, Italy) and a PhD in Economics and Management (University of Trento, Italy). His research interests include productivity analysis, regional and industrial policy evaluation, and firm strategy.

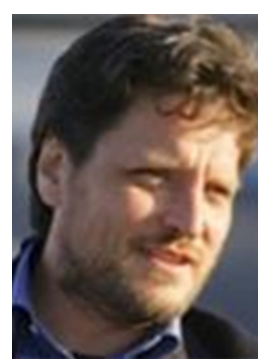

Roberto Gabriele is Associate Professor of Applied Economics at University of Trento, Italy. He holds a PhD in Economics and Management (Sant'Anna School of Advanced Studies). His research interests are in firms and industry dynamics, public policies evaluation. He uses micro econometrics, counterfactual models and agent based models to conduct his studies.

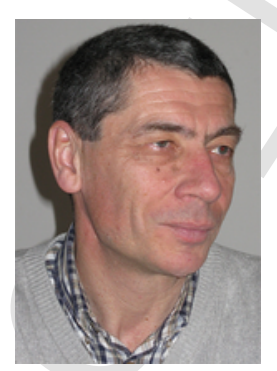

Enrico Zaninotto is Full Professor of Business and Management Economics at the University of Trento, Italy. Among his research interests, there are: Economic theory of organizations, and empirical study of the relationships between firm organization and productivity. 